\title{
The Effect of Religious Conflicts in Northern Nigeria on Public Health Outcomes: A Case Study of Cholera Outbreak
}

\author{
Adamu Nuhu, MBBS, MBA \\ Director, North-West Zone, \\ National Primary Health Care Development Agency Abuja, Nigeria \\ Kabir M. Yusuf, PhD \\ Department of Disease Control and Immunization, \\ National Primary Health Care Development Agency Abuja, Nigeria
}

Doi: 10.19044/esj.2018.v14n30p408 URL:http://dx.doi.org/10.19044/esj.2018.v14n30p408

\begin{abstract}
Violent conflicts, in most cases, pose an unquantifiable challenge to human health and health systems especially in developing countries. Complex humanitarian emergencies as a result of conflicts could severely have negative consequences on public health. Nigeria has faced series of threatening security challenges, but the one caused by the activities of the socalled Islamist sect, the Boko Haram (BH), remains protracted, especially in Borno, a State in the north-eastern part of the country. The resultant outcome is the internally displaced persons (IDPs) who have suffered from many diseases especially cholera, which has continued to ravage these displaced populations. Conflict can contribute to water shortage through the destruction of water sources, such as wells, reservoirs and laid pipes, and its contamination. This is happening on an already weak health system. Though cholera is easily treatable, concerted efforts by government and medical humanitarian agencies are urgently required to ameliorate the situation of the IDPs. An appropriate strategy of control of the transmission of cholera and emergency medical intervention can help alleviate the devastating effects. The management of cholera transmission include the supply of sufficient water sources, adequate sanitation, and a public health campaign to maximize the effects of these measures. One key health system challenge that could limit the effectiveness of the interventions would be the people. This paper focuses on studying the resultant large numbers of IDPs from the BH conflict, discussing cholera outbreak as a specific health issue, and presenting a focused humanitarian intervention to address this health need.
\end{abstract}


Keywords: Northern Nigeria, internally displaced persons (IDPs), BH religious conflicts, Cholera, humanitarian intervention

\section{Introduction}

Violent conflicts pose a challenge to human health and health systems (Siddarth, 2017). Complex humanitarian emergencies as a result of conflicts could severely give rise to public health consequences, population displacement, food scarcity, and the collapse of basic health services (Nicholas \& Anthony, 2000). Armed conflicts can also cause the displacement of people and an increase in infectious diseases (Okonkwo et al., 2009).

Countries which had experienced conflicts such as Yemen, Nepal and so on, mostly in the developing world, have been affected by a major cholera epidemic devastating the countries and have further exacerbated the humanitarian situation (Dureab et al., 2018). In practically all of these countries, the government's surveillance system is inadequate due to lack of access to non-government held territories, except if partners such as WHO are on ground to support surveillance in conflict zones (Sparrow et al., 2016).

Nigeria has faced series of threatening security challenges, but the one caused by the activities of the so-called Islamist sect, the Boko Haram $(\mathrm{BH})$, remains protracted. The sect claims responsibility for several bombings, gruesome killings, kidnappings, human rights violation, and other sinister activities especially in the northern parts of the country. The attacks have been on both the military and civil sections of the communities (Ahokegh, 2012; Shuaibu et al., 2015). The violent activities of the group, after several years of intense destruction of lives and properties, have now been subdued by concerted government efforts to less frequent but chronic conflict. Some of the after effects of the $\mathrm{BH}$ conflict have been migration of large numbers of people as internally displaced persons (IDPs). However, they also suffer from serious violations of human rights and dignity.

The BH was founded by an Islamic cleric, the late Muhammad Yusuf, in 2002 in Maiduguri, the capital city of Borno State, in the northeast of Nigeria (Ahokegh, 2012). It was initially a domestic-based insurgent group that later became bolder and more destructive after its clash with the Nigeria security agencies in 2009 that led to the killing of its leader, Muhammad Yusuf (Shuaibu et al., 2015). BH can therefore be seen as an outcome of Nigeria's religious conflict, and to some extent political, social, and economic problems. Studies have shown that abundance of natural resources are often associated with greater incidence of civil conflict, including other risk factors such as poverty, youth unemployment, militarization, ethnic dominance, diaspora, regime instability, geography, history, and regional conflict (Collier \& Sambanis, 2002). These factors are rife in the northeast region of Nigeria as 
reported by Okoro (2014). Arguably, the criticism of Collier's analysis centred on the unreliability of data from conflict-affected countries; the analysis being mono-dimensional, treating rebel groups as homogenous, and literally ignoring the role of government. However, the weight of the argument for the origin of the $\mathrm{BH}$ conflict in Nigeria will largely be based on the explanatory theory of ethnicity and identity (Shuaibu et al., 2015).

Global Conflict Tracker (2018) also places the BH conflict as sectarian, which falls into the ethnicity and identity theory. After the killing of Muhammad Yusuf, a new ringleader, Abubakar Shekau, emerged with a new religious ideology. Up till now, the BH's ideology seeks to purify Islam in Nigeria from their so-called heretical influences. They propagate among its followers the rejection of Western bid'ah (innovation) and shirk (polytheism), as reflected by their orientation. As such, anyone who does not follow BH's version of Islam is a target for killing. This new group continued to grow stronger and more radicalized in its approach in the country. It quickly expanded its base of operations outside Borno State to neighbouring contiguous States and farther on in the country. Indeed, it even claimed to have established links with international terrorist organizations such as Al-Shabaab and Al Qaeda. BH quickly introduced new methods of violence, which include that of suicide bombings, kidnappings, violent attacks on the police and the military at check points and even their barracks and other formations. BH's influence and activities became possible, in part, due to the deterioration in socio-economic situation of the Northeast Nigeria where the group is more prevalent (UN OCHA, 2015; Relief Web, 2017a).

The crisis in northeast Nigeria is one of the most severe in the world today. Since the beginning of the conflict, more than 20,000 people have been killed; more than 4,000 women and girls abducted; and it was estimated that more than 2 million people have been forcibly displaced from their homes and communities (Relief Web, 2018). The report further states that across the 6 affected States of Borno, Adamawa, Yobe, Bauchi, Gombe and Taraba, 10.2 million people were estimated to need humanitarian assistance in 2018, of whom 52\% are women and girls, and $48 \%$ are men and boys. Children constitute $63 \%$ of those needing assistance, while the most acute humanitarian needs are in Borno State where the crisis shows no sign of abating (Relief Web, 2017b). Humanitarian access to the conflict areas have been challenging due to restriction on the movement of aid workers and civilians, on-going attacks, and hard-to-reach geographic terrain - expansive sandy desert region and heavy forests especially during the rainy seasons.

This paper focuses on studying the resultant large numbers of internally displaced persons (IDPs) from the BH conflict, discussing cholera outbreak as a specific health issue, and presenting a focused humanitarian intervention to address this health need. 


\section{Study Area}

Nigeria is located in the West African sub-region, having an estimated projected total population of over 198 Million people (NPC, 2018). It consists of 36 States and the Federal Capital Territory, with an estimated more than 250 ethnic groups and tribes, each with their own culture and traditions, including different languages. There are, however, three major tribes; the Hausa-Fulani, Yoruba, and Igbo (Blench \& Dendo, 2003). These make up about $70 \%$ of the country's population. The country is broadly divided into the predominant Islamic north and Christian south, although other smaller religious groups including animists do exist within the country. The two predominant religions are further subdivided into various sects that had been and are still experiencing intra and inter-sectarian crisis over the years.

\section{Cholera among the IDPs resulting from the BH Conflict in Northern Nigeria}

Conflict can contribute to water shortage through the destruction of water sources, such as wells, reservoirs and laid pipes, and its contamination. The communities where IDPs are accommodated always experience extra burden due to its need for adequate water, sanitation, and hygiene resulting in increase in morbidity from diarrhoeal diseases. The IDPs camps were haphazardly put together with no basic amenities to cater for the number of people living there.

Conflict is usually characterized by forced migration, leaving populations in dire poverty, internally displaced or seeking asylum, having poor access to essential services, and consequentially vulnerable to infectious diseases (Okonkwo et al., 2009). Though Nigeria is rated as one of the largest economies in Africa going by its gross domestic product (NBS, 2018), it is still classified under the low middle-income countries (LMICs) globally (Vaggi, 2017). As a necessity, effective health services can only be delivered on functioning systems, which are often deficient in LMICs. The goals of health systems are health achievement, fairness of financial contribution, and responsiveness to the expectations of the population (Witter et al., 2017; Mundeva et al., 2018).

Cholera disproportionately affects LMICs due, in part, to lack of resources and barriers to access it. Public services and the institutions that provide essential services and infrastructure have collapsed in the areas where conflict has ravaged. Conflict situations present a multitude of risk factors that enhance disease emergence and transmission, over and above those in other resource-poor countries. Many of such conflicts facilitate the occurrence of cholera outbreaks (Levine et al., 2007; Abimbola et al., 2016; Khan \& Irwin, 2016). Many researchers have reported outbreak of many diseases in the country such as cholera that is also endemic throughout the year (Ali et al., 
2015; NCDC, 2017) in an already weak health system. There has been no accurate and reliable data source resulting in a distorted picture of the IDPs' assistance needs and an alarming lack of understanding of the country's displacement dynamics on the part of national authorities and the international community (Oluwasanmi \& Innocent, 2018). However, it was further reported that only about $30 \%$ of health facilities are functional in Borno State, where malaria, cholera, and other diseases affect population regularly, often in lifethreatening ways. Further estimates given show that nearly 800 facilities and 1,600 water supply sources have been destroyed. Most of the populations have not yet returned to the conflict-affected areas, in part, because they remain inhospitable. Although more IDP and refugee camps have been constructed to facilitate the massive exodus, the conditions faced by displaced persons in those government camps are far from ideal. In addition, there is a lack of basic emergency resources and clean drinking water, sanitation issues, food shortages, and overcrowding.

Deadly health risks are associated with these poor circumstances; people living in such close proximity in the camps have been exposed to periodic cholera outbreaks (Tappero \& Tauxe, 2011). Watson et al. and Sim (2007; 2013) have earlier reported that cholera outbreaks in populations displaced by man-made or natural disasters present a global health emergency due to their high risk, elevated rates of fatality, and their ability to carry cholera abroad. Refugee and internally displaced person (IDP) camps present a number of challenges: their inadequate water supply, poor sanitation, dense population, and lack of resources (Owoaje et al., 2016). There has been an outbreak of cholera in Borno State since August 2017 (Relief Web, 2017b). It was further reported that the most affected area has been the outskirts of Maiduguri, in the Muna Garage camp, which is home to some 32,000 IDPs. Other communes are also affected by the outbreak; such as Dikwa, Mafa, and Monguno. There were more than 4,800 suspected cases and 61 deaths as reported. Most reported cases are concentrated in the "Muna Corridor" in Maiduguri, which includes 15 sites for IDPs. By the WHO rapid assessment, the risk of spread in the Borno capital is high due to the congestion, poor infrastructure, and water/sanitation conditions in the area (Relief Web, 2018).

\section{Preventive Measures and Humanitarian Intervention for Cholera among the IDPs}

As reported by Sim (2013), refugee and IDP camps present a number of challenges: their inadequate water supply, poor sanitation, dense population, and lack of resources. Therefore, an appropriate strategy of control of the transmission of cholera and emergency medical intervention can help alleviate the devastating effects. The management of cholera transmission included the supply of sufficient water sources, adequate sanitation, and a 
public health campaign to maximize the effects of these measures. Urgent medical intervention is necessary to ease the burden of disease on refugee and IDP camps, especially during a cholera outbreak (Oluwole, 2017).

The Nigeria and Borno State government, in collaboration with humanitarian organizations and development partners, jointly supported and contain the outbreak through: dissemination of cholera prevention messages to the population; early detection and treatment of suspected cases; providing oral rehydration therapy for the affected; improving and protecting drinking water sources; provision of improved sanitation and hygiene facilities. It is also very vital that the source and site of the cholera infection was quickly detected. Water is a major source of transmission of the disease. However, there is need for sufficiency of water in terms of minimum quantity required as well as the quality. In these conditions, the provision of portable water is a major challenge. Hence, there is the need for urgent treatment of the available water with chlorine tablets and sinking of wells and boreholes. The IDPs are living in cramped and congested environment in the camps. This further creates public health risk in terms of other disease outbreaks. Disease surveillance and monitoring of health situation are a major priority.

Very few health teams who work within the IDP camps conduct health promotion, explaining how cholera spreads. Raising awareness about the cholera situation is essential. The IDPs are also reminded of good hygiene measures such as hand washing with soap and clean water, cook food very well, and the use of latrines or toilets for defecation. Cases of cholera are treated with oral rehydration salts. In order to treat infected patients as soon as possible, Alliance for International Medical Action (ALIMA) installed oral rehydration points in Muna Garage, Muna Customs, and two sites in Monguno (Relief Web, 2017c). ALIMA had set up four observation sites in Monguno. When suspected cases of cholera are detected, the severity of the disease is determined. Non-severe cases may stay at the center, where they are kept under observation and are treated with oral rehydration salts. The reduction of person-to-person transmission requires individual hygiene and the disinfection of potential sources of contamination, such as dirty water or in marketplaces. Unfortunately, because of densely packed population, IDPs had a more rapid spread of cholera and resultant higher morbidity and mortality. High case fatality rates (CFR) were linked to the challenge of limited access to health care by the IDPs.

The Nigeria National Emergency Management Agency (NEMA), Red Cross, Medecins Sans Frontieres (MSF), ALIMA, and other humanitarian workers have jointly contributed, under the coordination of NEMA, Borno State Government and security agents, to ensure IDPs receive adequate assistance. Efforts are put to ensure full access and intensification of water supply, sanitation, and hygiene (WASH) activities in the IDP camps. 
Table 1. Logframe for the Cholera Intervention Project

\begin{tabular}{|c|c|c|c|}
\hline Objectives & Indicators & $\begin{array}{l}\text { Source of } \\
\text { Verification }\end{array}$ & Advocacy \\
\hline $\begin{array}{l}\text { Overall } \\
\text { Reduced Cholera } \\
\text { mortality in the IDP } \\
\text { Camps }\end{array}$ & $\begin{array}{l}\text { CFR of }<2.4 \% \text { by mid } \\
2017\end{array}$ & $\begin{array}{l}\text { Nigeria IDSR } \\
\text { Weekly Report \& } \\
\text { WHO Data for Afro } \\
\text { Region }\end{array}$ & $\begin{array}{l}\text { Cholera treatment } \\
\text { available at camps }\end{array}$ \\
\hline $\begin{array}{l}\text { Impact } \\
\text { Reduced Cholera cases } \\
\text { among IDPs }\end{array}$ & $\begin{array}{l}\text { AR of }<54.7 / 100,000 \\
\text { IDPs population by mid } \\
2017\end{array}$ & $\begin{array}{l}\text { Nigeria IDSR } \\
\text { Weekly Report \& } \\
\text { WHO Data for Afro } \\
\text { Region }\end{array}$ & $\begin{array}{l}\text { Cholera case detection } \\
\text { and diagnosis }\end{array}$ \\
\hline $\begin{array}{l}\text { Output } \\
\text { Use of clean water and } \\
\text { improved sanitation } \\
\text { facilities }\end{array}$ & $\begin{array}{l}\text { Proportion of IDPs } \\
\text { practicing WASH }\end{array}$ & $\begin{array}{l}\text { IDPs population } \\
\text { survey }\end{array}$ & $\begin{array}{l}\text { Functional sources of } \\
\text { clean water and } \\
\text { improved sanitation } \\
\text { facilities }\end{array}$ \\
\hline $\begin{array}{l}\text { Outcome } \\
\text { IDPs are protected from } \\
\text { contracting Cholera }\end{array}$ & $\begin{array}{l}\text { Reduction in AR } \\
\text { amongst IDPs } \\
\text { population }\end{array}$ & $\begin{array}{l}\text { Nigeria IDSR } \\
\text { Weekly Report \& } \\
\text { WHO Data for Afro } \\
\text { Region }\end{array}$ & $\begin{array}{l}\text { Health \& } \\
\text { Humanitarian } \\
\text { Agencies provide } \\
\text { diagnostics }\end{array}$ \\
\hline $\begin{array}{l}\text { Input } \\
\text { Provision of clean water } \\
\& \text { sanitation facilities, } \\
\text { health promotion }\end{array}$ & $\begin{array}{l}\text { Proportion of IDPs } \\
\text { practicing WASH }\end{array}$ & $\begin{array}{l}\text { IDPs population } \\
\text { survey }\end{array}$ & $\begin{array}{l}\text { Provision of chlorine } \\
\text { tablets and sinking of } \\
\text { wells and boreholes }\end{array}$ \\
\hline
\end{tabular}

Adaptation from Howard et al. (2012)

From the above table, the mean overall CFR for cholera reported in Africa in the $2000-2005$ period was $2.4 \%$, and the WHO acceptable rate was 1\%. Cholera Attack Rate (AR) for Borno State was 54.7/100,000 population as reported by Dalhat et al. (2014). Outbreaks of cholera in Borno State spread to contiguous States of Yobe, Bauchi, and Adamawa. Intensive surveillance activities were stepped up to contain and curtail spread. Source of verification was by using data from the Nigeria integrated disease surveillance and response (IDSR) Weekly Report and the WHO Data for the Afro Region. While cholera treatment was made available at the camp, Health and Humanitarian Agencies supported government in the cholera case detection and the provision of diagnostics at the camps. Chlorine tablets are freely distributed for water treatment and wells, and boreholes were sunk as a matter of urgency to provide safe drinking water. The Agencies representing the government of Borno State and NEMA supported the population commission to enumerate the numbers of the IDPs.

Having been able to achieve the above, one key health system challenge that limited the effectiveness of the above interventions was the people (human resource). Other challenges that arose ranged from not following health education messages by the IDPs, humanitarian medical workers cutting edges, and uncoordinated efforts by all concerned. The Nigerian and Borno State governments need to put in more resources to 
ameliorate the plight of the IDPs and not to depend on humanitarian agencies only. Apart from the management of the cholera, sufficient food supply needs to reach the IDPs. The generation and flow of reliable and timely health information for decision-making from the IDPs camps is needed. This intervention project is proposed to span over not more than 3 months to control and contain the cholera epidemic. Therefore, behavioural change messages for health promotion and education will continue to help in preventing future incidences.

\section{Conclusion}

The sectarian conflict and its effects on the population by the so-called Islamist sect, the Boko Haram $(\mathrm{BH})$, remains protracted, especially in the northeast Borno State of Nigeria. The killing of the leader of the $\mathrm{BH}$, Muhammad Yusuf, has resulted in Nigeria's religious conflict. The resultant IDPs have suffered from many diseases but cholera has continued to ravage these displaced populations. This is happening on an already weak health system where cholera has been endemic in the country over the recent past. Though cholera is easily treatable, concerted efforts by government and medical humanitarian agencies are urgently required to ameliorate the situation of the IDPs. Hence, one key health system challenge that could limit the effectiveness of the interventions would be the people.

\section{References:}

1. Abimbola, S., Ogunsina, K., Charles, A., Negin, O. J. \& Martiniuk, A. (2016). Information, regulation and coordination: Realist analysis of efforts of community health committees to limit informal health care providers in Nigeria. Fourth Global Symposium on Health System Research.

2. Ahokegh, A. F. (2012). Boko Haram: A 21st century challenge in Nigeria. European scientific journal. (8)21: 1857 - 7881.

3. Ali, M., Nelson, A. R., Lopez, A. L. \& Sack, D. A. (2015). Updated Global Burden of Cholera in Endemic Countries. PLoS Negl Trop Dis., 9(6): e0003832.

4. Blench, R. \& Dendo, M. (2003). Position paper: The dimensions of ethnicity, language and culture in Nigeria. Nigeria: Drivers of Change Component Three - Output 28 Prepared for DFID, Nigeria [FINAL REPORT]. 8, Guest Road Cambridge CB1 2AL United Kingdom. http://www.rogerblench.info/RBOP.htm

5. Collier, P. \& Sambanis, N. (2002). Understanding Civil War: A New Agenda. Journal of Conflict Resolution, 46; 3.

6. Dalhat, M. M., Isa, A.N., Nguku, P., Nasir, S. G., Urban, K., Abdulaziz, M., Dankoli, R. S., Nsubuga, P. \& Poggensee, G. (2014). 
Descriptive characterization of the 2010 cholera outbreak in Nigeria. BMC Public Health, 14:1167.

7. Dureab, F., Shibib, K., Al-Yousufi, R. \& Jahn, A. (2018). Yemen: Cholera outbreak and the ongoing armed conflict. J Infect Dev Ctries 12:397-403. doi: https://doi.org/10.3855/jidc.10129

8. Global Conflict Tracker (2018). Retrieved from https://www.cfr.org/interactives/global-conflict-tracker\#!/globalconflict-tracker

9. Howard, N., Sondorp, E. \& Veen, A. (2012). Understanding Public Health series. Conflict and Health, p.112-123.

10. Jocelynn, R. (2015). The Boko Haram Insurgency and The Hardships Faced by Its Victims. Ifriqiya. Africa Research Program,(1)8.

11. Jordan, W. T, Robert, V. \& Taux, R. V. (2011). Lessons Learned during Public Health Response to Cholera Epidemic in Haiti and the Dominican Republic. Emerg Infect Dis., 17(11): 2087-2093. doi: 10.3201/eid1711.110827

12. Khan, S. K. \& Irwin, R. (2016). Challenges in access and provision of medical aid for children after natural disasters in low and lower-middle income countries: a scoping review. Degree Project for the Master's Program in Global Health. Department of Public Health Sciences.

13. Levine, A. C., Presser, D. Z., Rosborough, S., Ghebreyesus, T. A. \& Davis, M. A. (2007). Understanding barriers to emergency care in lowincome countries: view from the front line. Prehosp Disaster Med, 2(5):467-70.

14. Mundeva, H., Snyder, J., Ngilangwa, D. P. \& Kaida, A. (2018). Ethics of task shifting in the health workforce: exploring the role of community health workers in HIV service delivery in low- and middleincome countries. BMC Medical Ethics; 19:71 https://doi.org/10.1186/s12910-018-0312-3

15. NBS (2018). National Bureau of Statistics. Retrieved from http://www.nigerianstat.gov.ng/

16. NCDC (2017). First Annual Report of the Nigeria Centre for Disease Control. Retrieved from www.ncdc.gov.ng/themes/common/docs/protocols/78_1515412191.p df

17. Nicholas, B. \& Anthony, B. Z. (2000). Public health and humanitarian interventions: developing the evidence base. BMJ,(321)7253: 101105.

18. NPC (2018). Nigerian population. Retrieved from http://population.gov.ng/

19. Okonko, I. O., Donbraye, E., Babalola, E. T., Mejeha, O.K., Fadeyi, A., Udeze, A. O., Garba, K. N., Fowotade, A. \& Adekolurejo, O.A. 
(2009). Conflict and the spread of emerging infectious diseases: Where do we go from here? African Journal of Microbiology Research,(3)13: 1015-1028.

20. Okoro, E. R. (2014). Terrorism and governance crisis: The Boko Haram experience in Nigeria. African Journal on Conflict Resolution,(14)2:103 - 127.

21. Oluwasanmi, O. I. \& Innocent, E.O. (2018). Rehabilitation of IDPs in North East Nigeria: Challenges and Prospects. Retrieved from www.researchgate.net/project

22. Oluwole, I. (2017). Rehabilitation of internally displaced persons, in Nigeria's northeast: challenges and prospects. Socialscientia Journal of the Social Sciences and Humanities. 10.13140/RG.2.2.26636.82562.

23. Owoaje, E.T., Uchendu, O. C., Ajayi, T. O. \& Cadmus, E. O. (2016). A review of the health problems of the internally displaced persons in Africa. Niger Postgrad Med J,23:161-71.

24. Relief Web (2017a). North-eastern Nigeria's Borno State has been suffering from an outbreak of cholera since August 16, 2017. Retrieved from

https://reliefweb.int/sites/reliefweb.int/files/resources/geo_79.pdf

25. Relief Web (2017b). Nigeria: ALIMA responds to cholera outbreak in Borno State. Retrieved from. https://reliefweb.int/report/nigeria/nigeria-alima-responds-choleraoutbreak-borno-state

26. Relief web (2017c). Impact of insurgency in Northeast Nigeria: Scenarios: Possible developments in northeast Nigeria over the next 9 months (to June 2017) 03 October 2016. Retrieved from https://reliefweb.int/report/nigeria/impact-insurgency-northeastnigeria-scenarios-possible-developments-northeast-nigeria

27. Relief Web (2018). Nigeria: 2018 Humanitarian Needs Overview. Retrieved from https://reliefweb.int/report/nigeria/nigeria-2018humanitarian-needs-overview

28. Shuaibu, S. S., Mohd, A.S. \& Abdullahi, Y. S. (2015). The Impact of Boko Haram Insurgency on Nigerian National Security. International Journal of Academic Research in Business and Social Sciences, (5)6: $2222-6990$.

29. Siddarth D. (2017). Conflict in South Asia and its impact on health. BMJ,357 doi: https://doi.org/10.1136/bmj.j1537.

30. Sim, C. (2013). Control and Intervention of Cholera Outbreaks in Refugee Camps. Global Societies Journal, e-ISSN: 2373-7611.

31. Sparrow, A., Almilaji, K., Tajaldin, B., Teodoro, N. \& Langton, T. (2016). Cholera in the time of war: implications of weak surveillance 
in Syria for the WHO's preparedness - a comparison of two monitoring systems. BMJ Global journals; vol (1)3.

32. UN OCHA (2015). Nigeria, Humanitarian Needs Overview. Retrieved from

33. Vaggi, G. (2017). The rich and the poor: A note on countries' classification. PSL Quarterly Review, vol. (70) 279: 59-82.

34. Witter, S., Govender, V., Ravindran, T. K. S. \& Yates, R. (2017). Minding the gaps: health financing, universal health coverage and gender. Health Policy and Planning, 32(5): 4-12. 